\title{
Primary Urinary Tract Lymphoma: Rare but Aggressive
}

\author{
KONSTANTINOS LONTOS ${ }^{1}$, ANASTASIA TSAGIANNI ${ }^{2}$, PAVLOS MSAOUEL ${ }^{3}$, \\ LEONARD JOSEPH APPLEMAN ${ }^{1}$ and DIMITRIOS NASIOUDIS ${ }^{4}$ \\ ${ }^{1}$ Division of Hematology/Oncology, and ${ }^{2}$ Division of General Internal Medicine, \\ University of Pittsburgh Medical Center, Pittsburgh, PA, U.S.A.; \\ ${ }^{3}$ Division of Cancer Medicine, The University of Texas MD Anderson Cancer Center, Houston, TX, U.S.A.; \\ ${ }^{4}$ Department of Obstetrics and Gynecology, University of Pennsylvania, Philadelphia, PA, U.S.A.
}

\begin{abstract}
Background: Primary urinary tract lymphoma (PUTL) is an uncommon disease with only a few case reports in the literature. Materials and Methods: Information about 1,264 patients diagnosed between 1983 and 2013 with PUTL was extracted from the Surveillance, Epidemiology and End Results database. Kaplan-Meier curves and multivariable regression analysis were used to analyze the survival and identify prognostic factors. A comparison of nodal diffuse large B-cell lymphoma (DLBCL) with PUTL $D L B C L$ was performed. In addition, we compared the characteristics of kidney and bladder lymphoma. Results: PUTL incidence was 1 casel1,000,000 people per year. $D L B C L$ was found to be the predominant histology. Fiveyear overall survival and cancer-specific survival were $49 \%$ and $58 \%$, respectively. DLBCL histology, male gender, stage III-IV disease, and advanced age were found to be poor prognostic factors. Surgery may be beneficial. Urinary tract $D L B C L$ has a worse prognosis than nodal DLBCL. Conclusion: To our knowledge, this is the largest populationbased study of PUTL in the literature. The survival of patients has not improved in the era of modern therapies therefore new treatments are needed.
\end{abstract}

Non-Hodgkin lymphomas (NHL) are hematological malignancies that can arise either from the lymph nodes (nodal) or other organs (extranodal). Based on an analysis of the National Cancer Institute's Surveillance, Epidemiology, and End Results (SEER) database, 72240 new cases of NHL will be diagnosed in 2017, while 20,140 people will die of the disease (1). Extranodal lymphoma comprises on average

Correspondence to: Konstantinos Lontos, MD, UPMC Cancer Pavilion, 5150 Centre Avenue, Room 463, Pittsburgh, PA 15232, U.S.A.E-mail: lontosk@upmc.edu

Key Words: Kidney lymphoma, renal lymphoma, bladder lymphoma.
$25-35 \%$ of NHLs, with the most frequent sites being the skin, small intestine and stomach (2).

Primary urinary tract lymphoma (PUTL), first described in 1953 (3), is a very rare entity, with only a few case reports in the literature $(4,5)$. Genitourinary tract NHLs represent $8.4 \%$ of extranodal lymphomas (6). To elucidate the demographic, survival outcomes, and prognostic factors of patients with PUTL, we performed a retrospective analysis using data deriving from a multi-institutional, populationbased cancer database.

\section{Materials and Methods}

The SEER Program of the National Cancer Institute collects information on cancer incidence and survival from 18 registries (Alaska Native Tumor Registry, Arizona Indians, Cherokee Nation, Connecticut, Detroit, Georgia Center for Cancer Statistics, Greater Bay Are Cancer Registry, Greater California, Hawaii, Iowa, Kentucky, Los Angeles, Louisiana, New Jersey, New Mexico, Seattle-Puget Sound, Utah) (7). It covers approximately $28 \%$ of the current US population based on the 2010 census. The SEER data are de-identified and available to the public for research purposes.

Eligible cases of PUTL were identified using ICD-O-3 codes (9590/3-9823/3) and topographical codes (64.9-68.9) from 1983 to 2013. Disease of the prostate was excluded as it is part of the male reproductive system. Patients diagnosed before 1983 were excluded due to unavailability of staging information according to the Ann Arbor system. Moreover, cases without active follow-up (diagnosis obtained from autopsy or death certificates), unknown Ann-Arbor stage, and those without histological confirmation of the disease were excluded. Demographic, clinical and pathological findings, and survival data were exported from the database using the case-listing option. The primary site was classified as either kidney, renal pelvis, ureter, or bladder. Treatment characteristics of patients with PUTL (administration of radiation therapy and performance of cancerdirected surgery) were also extracted. Unfortunately, the SEER database does not provide data on the administration of chemotherapy. In general, the captured treatment data exhibit low sensitivity but high positive predictive value (8). Following the National Comprehensive Cancer Network (NCCN)-IPI prognostic model for diffuse large B-cell lymphoma (DLBCL) (9), patients were categorized into three age groups, $<60,60-75$ and $>75$ years 
old. Cases were also dichotomized based on the year of diagnosis; 2000 was used as a cut-off as in December of 2000 the first landmark study on the addition of rituximab to standard chemotherapy was presented at the American Society of Hematology (ASH) Meeting (10). In addition, according to an epidemiological study, the use of rituximab before that date was infrequent (11). For comparison of survival with nodal DLBCL, additional cases were extracted using the 9680/3 code and the NHL - Nodal 'Site recode ICD-O-3/WHO 2008' category. Similar exclusion criteria were applied as described above.

The SEER database records survival as the number of months elapsed from the day of tumor diagnosis to the day of death or last contact. For the estimation of cancer-specific survival (CSS), only death attributable to the lymphoma was considered to be an event. To prevent confounding, we excluded patients diagnosed with more than one primary tumor from the survival analysis. Survival curves were estimated by the Kaplan-Meier method and were compared using the log-rank test. Cox proportional hazard models were constructed to identify independent predictors of cancer-specific mortality. Cases with missing data for one or more of the variables were excluded from the multivariable regression analysis. To allow adequate power for the Kaplan-Meier curves and the Cox model, kidney cases were grouped with renal pelvis cases, whereas ureter cases were grouped with bladder cases. We did not use this grouping when presenting descriptive statistics or for the comparison between kidney and bladder lymphoma. Statistical analysis was performed with IBM SPSS Statistics 24 software (IBM Corp., Armonk, NY, USA) and a $p$-value of less than 0.05 was considered statistically significant. Incidence data and trends were calculated through SEER*Stat Version 8.3.4 (12), using all 18 registries from 2000 to 2014. Chi-square tests were utilized to compare categorical variables and Mann-Whitney U-test and Kruskal-Wallis test were used to compare continuous variables.

\section{Results}

Incidence. The age-adjusted incidence rate of PUTL was calculated to be 1 case $/ 1,000,000$ people per year in the US population. The yearly incidence of kidney lymphoma was 0.7 cases while that of bladder lymphoma was 0.3 . Trends in yearly changes were examined and no site was proven to have a statically significant annual percentage change. Among different races, Hispanics, Asians/Pacific Islanders and Whites exhibited the highest annual incidence rates (1.6, 1.6 and 1.1, respectively) while Blacks and American Indians/ American Natives exhibited the lowest (0.7 and 0.4, respectively).

Demographics, histology and clinical characteristics. A total of 1,264 eligible cases of PUTL diagnosed between 1983 and 2013 were identified. Patient demographics and clinicopathological characteristics are listed in Table I. The OS and CSS at 5 years were $49 \%$ and 58\%, respectively. There was a slight male predominance $(57 \%)$. Median age at presentation was 71 years, with only $24 \%$ of cases occurring in patients younger than 60 years old. Most patients were White $(78.3 \%)$ and $77 \%$ were diagnosed after 2001 . The
Table I. Clinical and demographic characteristics of patients with primary urinary tract lymphoma $(n=1,264)$.

\begin{tabular}{|c|c|c|}
\hline Characteristic & Subgroup & $\mathrm{n}(\%)$ \\
\hline \multirow[t]{3}{*}{ Age } & $<60$ Years & $309(24 \%)$ \\
\hline & 60-75 Years & $507(40 \%)$ \\
\hline & $>75$ Years & $448(36 \%)$ \\
\hline \multirow[t]{6}{*}{ Race } & White & $989(78.3 \%)$ \\
\hline & Black & $90(7.2 \%)$ \\
\hline & Hispanic & $101(8 \%)$ \\
\hline & American Indian/Alaskan & $4(0.3 \%)$ \\
\hline & Asian or Pacific Islander & $77(6 \%)$ \\
\hline & Unknown & $3(0.2 \%)$ \\
\hline \multirow[t]{5}{*}{ Marital status } & Married & $693(55 \%)$ \\
\hline & Single & $179(14 \%)$ \\
\hline & Widowed & $251(20 \%)$ \\
\hline & Divorced & $95(7 \%)$ \\
\hline & Unknown & $46(4 \%)$ \\
\hline \multirow[t]{2}{*}{ Year of diagnosis } & Before 2000 & $293(23 \%)$ \\
\hline & $2000 \mathrm{On}$ & $971(77 \%)$ \\
\hline \multirow[t]{4}{*}{ Site } & Kidney & $896(70.8 \%)$ \\
\hline & Pelvis & $22(1.7 \%)$ \\
\hline & Ureter & $20(1.6 \%)$ \\
\hline & Bladder & $326(25.9 \%)$ \\
\hline \multirow[t]{4}{*}{ Ann-Arbor stage } & I & $500(40 \%)$ \\
\hline & II & $279(22 \%)$ \\
\hline & III & $78(6 \%)$ \\
\hline & IV & $407(32 \%)$ \\
\hline \multirow[t]{3}{*}{ Cancer-directed surgery } & Yes & $732(57.9 \%)$ \\
\hline & No & $529(41.9 \%)$ \\
\hline & Unknown & $3(0.2 \%)$ \\
\hline \multirow[t]{3}{*}{ Radiation } & Yes & $143(11.3 \%)$ \\
\hline & No & $1103(87.3 \%)$ \\
\hline & Unknown & $18(1.4 \%)$ \\
\hline \multirow[t]{5}{*}{ Treatment } & Surgery only & $442(35 \%)$ \\
\hline & Radiation only & $64(5.1 \%)$ \\
\hline & Both & $79(6.2 \%)$ \\
\hline & Unknown & $19(1.5 \%)$ \\
\hline & Neither & $660(52.2 \%)$ \\
\hline \multirow[t]{11}{*}{ Type of lymphoma } & DLBCL & $656(51.9 \%)$ \\
\hline & MALT & $158(12.5 \%)$ \\
\hline & Follicular & $119(9.4 \%)$ \\
\hline & NHL, NOS & $118(9.3 \%)$ \\
\hline & Malignant lymphoma, NOS & $68(5.4 \%)$ \\
\hline & CLL & $57(4.5 \%)$ \\
\hline & Burkitt & $31(2.5 \%)$ \\
\hline & Other NHL, B-cell & $29(2.3 \%)$ \\
\hline & Hodgkin & $11(0.9 \%)$ \\
\hline & Other lymphomas & $10(0.8 \%)$ \\
\hline & Other NHL, T-cell & $7(0.5 \%)$ \\
\hline \multirow[t]{2}{*}{ Gender } & Female & $540(43 \%)$ \\
\hline & Male & $724(57 \%)$ \\
\hline
\end{tabular}

DLBCL, Diffuse large B-cell lymphoma; MALT, mucosal-associated lymphoid tissue; NHL, non-Hodgkin's lymphoma; NOS, not otherwise specified; CLL, chronic lymphocytic leukemia.

predominant site of involvement was the kidney (70.8\%). The most frequently encountered stage at presentation was stage I ( $40 \%$ of cases), followed by stage IV (32\% of cases). 


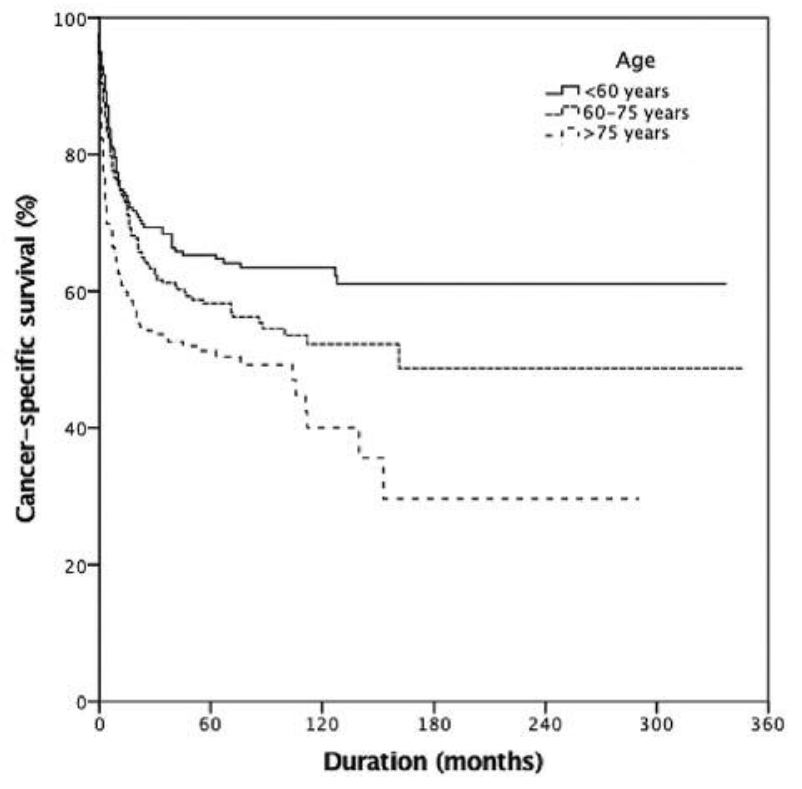

Figure 1. Cancer-specific survival of patients with primary urinary tract lymphoma stratified by age $(N=846, p<0.001)$. Five-year cancerspecific survival was $65 \%, 58 \%$ and $51 \%$ for those aged $<60,60-75$ and $>75$ years, respectively.

Stratification by age according to NCCN-IPI demonstrated well-separated survival Kaplan-Meier curves (Figure $1, p<0.001$ ). The 5-year CSS for patients $<60$ years old was $65 \%$, for these aged $60-75$ years $58 \%$ and for those $>75$ years $51 \%$. The 5 -year CSS was $69 \%, 58 \%, 53 \%$ and $47 \%$ for stage I, II, III and IV, respectively (Figure 2, $p<0.001)$. The majority of cases did not receive radiation therapy or undergo cancer-directed surgery (52.2\%), while $35 \%$ of the patients only underwent cancer-directed surgery, $5.1 \%$ received only radiation therapy, and $6.2 \%$ had multimodal treatment (radiation therapy combined with cancer-directed surgery).

In terms of histology, the three most prevalent types of PUTL were DLBCL (51.9\%) followed by marginal zone lymphoma of mucosa-associated lymphoid tissue (MALT) lymphoma $(12.5 \%)$ and follicular lymphoma (9.4\%). Fiveyear CSS rates were $56 \%$ for patients diagnosed with Burkitt lymphoma, $78 \%$ for those with chronic lymphocytic lymphoma (CLL)/small lymphocytic lymphoma, 51\% for those with DLBCL, $71 \%$ for those with follicular and $88 \%$ for those with MALT (Figure 3, $p<0.001$ ). The incidence of most types of PUTL peaked among patients in their $70 \mathrm{~s}$ (median age of 71 years for DLBCL and follicular lymphoma, 71.5 years for MALT, and 73 years for CLL), with the exception of Burkitt lymphoma which had a median age of 41 years $(p<0.001)$.

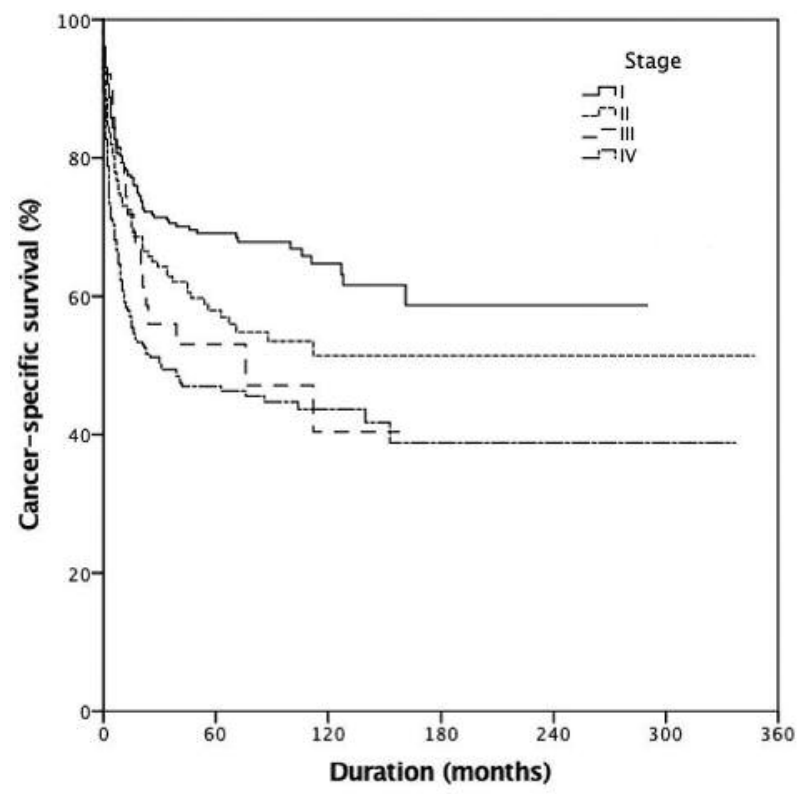

Figure 2. Cancer-specific survival of patients with primary urinary tract lymphoma (PLUT) stratified by stage $(N=846, p<0.001)$. Five-year cancer-specific survival was $69 \%, 58 \%, 53 \%$ and $47 \%$ for patients with stage I, II, III and IV disease, respectively.

Multivariable analyses are presented in Table II. Variables that were included were age, race, treatment, site, stage, year, gender and type of lymphoma. Older age groups had worse CCS. Male gender also conferred a worse prognosis [hazard ratio (HR) $1.48,95 \%$ confidence interval $(\mathrm{CI})=1.13-1.94]$, whereas race did not affect the outcomes. Compared with stage III-IV, patients with stage I disease had better CSS. Stage II did not reach statistical significance. Cancer-directed surgery and multimodal treatment (surgery plus radiation therapy) were associated with a mortality benefit, while the administration of radiation therapy alone did not improve outcomes. DLBCL carried the worst prognosis, with follicular and MALT lymphomas demonstrating better outcomes. There was no clear benefit of improved survival in the rituximab era $(\mathrm{HR}=0.80,95 \% \mathrm{CI}=0.60-1.07)$.

Bladder versus kidney lymphoma. The majority of patients with bladder lymphoma were female $(58.7 \%)$ whereas the majority with lymphoma of the kidney were male $(63.3 \%)$ $(<0.001)$. Moreover, most bladder lymphomas were diagnosed at stage I $(61.3 \%)$ compared to only $31.4 \%$ of kidney lymphomas $(p<0.001)$. MALT lymphomas were more common in the bladder $(22.7 \%$ vs. $12.7 \%, p<0.001)$. Patients with bladder lymphomas received more interventions (surgery $61 \%$ vs. $33.8 \%$, radiation $22 \%$ vs. $7.3 \%, p<0.001$ ). Five-year CCS rates were $63 \%$ and $56 \%$ for patients with bladder and 


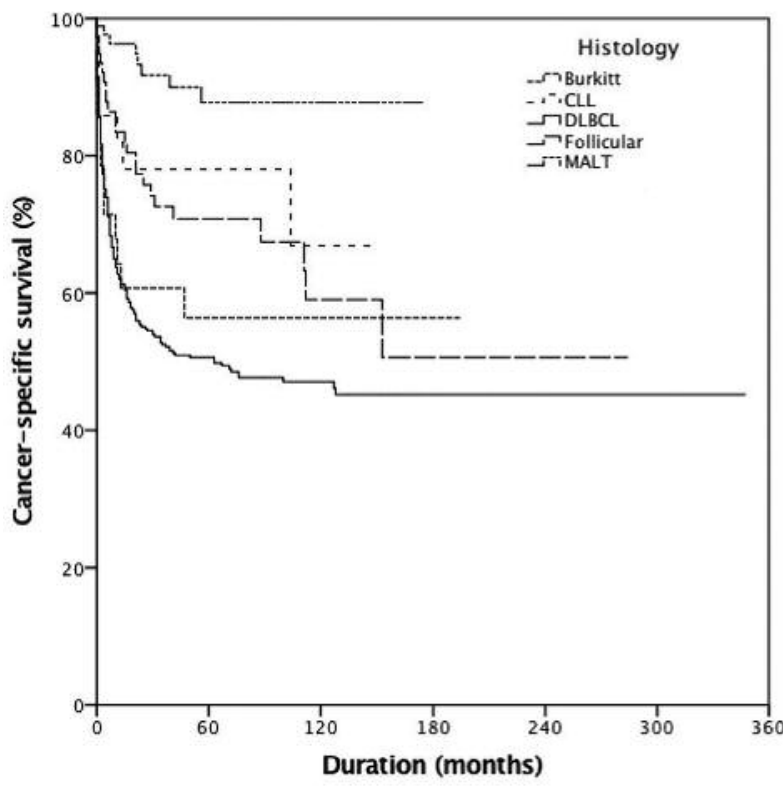

Figure 3. Cancer-specific survival of patients with primary urinary tract lymphoma stratified by histology $(N=846, p \leq 0.001)$. Five-year cancerspecific survival was $56 \%, 78 \%, 51 \%, 71 \%$ and $88 \%$ for patients with Burkitt lymphoma, chronic lymphocytic lymphoma (CLL.), diffuse large $B$-cell lymphoma (DLBCL), follicular and mucosa-associated lymphoid tissue lymphoma (MALT), respectively.

kidney lymphoma, respectively $(p=0.117)$. There was no significant difference in CSS between the two groups. A detailed comparison of demographic, clinicopathological and survival data between the two sites is presented in Table III.

Comparison of PUTL with nodal DLBCL. As DLBCL was the most common type of PUTL, 47,437 cases of microscopically confirmed nodal DLBCL were extracted from the SEER database (1983-2013). Following stratification by Ann-Arbor stage, patients with early-stage disease (stage I-II) and nodal DLBCL had 5-year CCS of $69 \%$ compared to $59 \%$ in patients with urinary tract DLBCL lymphoma (Figure $4 \mathrm{~A}, p<0.001$ ). Similarly, among patients with late stage disease (stage III-IV), urinary tract DLBCL had worse 5-year CSS (39\% vs. 46\%) compared with nodal DLBCL (Figure 4B, $p=0.03$ ). Multivariable analyses controlling for year of diagnosis, gender, disease stage, patient age and race showed that patients with urinary tract DLBCL had worse CSS compared with patients with nodal DLBCL (HR=1.26, 95\% CI=1.10-1.44).

\section{Discussion}

To our knowledge, this is the first large-scale population study of PUTL with $>1,000$ cases from several registries
Table II. Cox proportional hazards model for cancer-specific survival in patients with primary urinary tract lymphoma.

\begin{tabular}{lcccc}
\hline & Variable & Hazard ratio & $95 \%$ CI & $p$-Value \\
\hline Histology & DLBCL & Referent & & - \\
& Follicular & 0.48 & $0.31-0.74$ & 0.001 \\
Gender & MALT & 0.16 & $0.08-0.33$ & $<0.001$ \\
& Female & Referent & & - \\
Year & Male & 1.48 & $1.13-1.94$ & 0.004 \\
& $1983-2000$ & Referent & & - \\
Stage & 2001-2013 & 0.80 & $0.60-1.07$ & 0.138 \\
& I & 0.55 & $0.40-0.76$ & $<0.001$ \\
& II & 0.73 & $0.53-1.01$ & 0.06 \\
Site & III-IV & Referent & & - \\
Treatment & Bladder & Referent & & - \\
& Kidney & 0.77 & $0.55-1.07$ & 0.117 \\
& No radiation or & Referent & & - \\
& surgery & & & \\
& Only Surgery & 0.70 & $0.53-0.93$ & 0.015 \\
& Only Radiation & 0.84 & $0.49-1.43$ & 0.515 \\
Race & Surgery and & 0.41 & $0.22-0.77$ & 0.005 \\
& radiation & & & \\
Age & Non-White & Referent & & - \\
& White & 0.90 & $0.66-1.23$ & 0.513 \\
& $<60$ & Referent & & - \\
& $\quad 60-75$ & 1.97 & $1.40-2.78$ & $<0.001$ \\
& $>75$ & 2.72 & $1.91-3.90$ & $<0.001$ \\
\hline
\end{tabular}

CI, Confidence interval; DLBCL, diffuse large B-cell lymphoma; MALT, mucosal-associated lymphoid tissue.

Table III. Comparison of patients with bladder versus kidney primary urinary tract lymphoma.

\begin{tabular}{lcccc}
\hline & Characteristic & Bladder & Kidney & $p$-Value \\
\hline Age, years & Median & 76 & 70 & $<0.001$ \\
Gender, n (\%) & Female & $58.7 \%$ & $36.7 \%$ & $<0.001$ \\
& Male & $41.3 \%$ & $63.3 \%$ & \\
Stage, n (\%) & I & $61.3 \%$ & $31.4 \%$ & $<0.001$ \\
& II & $14.7 \%$ & $24.8 \%$ & \\
& III & $4.6 \%$ & $6.8 \%$ & \\
Histology, n (\%) & IV & $19.4 \%$ & $37 \%$ & \\
& DLBCL & $60.3 \%$ & $65.8 \%$ & $<0.001$ \\
& Follicular & $7.1 \%$ & $13.4 \%$ & \\
& MALT & $22.7 \%$ & $12.7 \%$ & \\
& Burkitt & $2.1 \%$ & $3.4 \%$ & \\
Treatment, n (\%) & CLL & $7.8 \%$ & $4.7 \%$ & \\
& No surgery or & $32.9 \%$ & $52.2 \%$ & $<0.001$ \\
& radiation & & & \\
& Only surgery & $43.9 \%$ & $31.6 \%$ & \\
& Only radiation & $4.9 \%$ & $5.1 \%$ & \\
& Surgery and & $17.1 \%$ & $2.2 \%$ & \\
& radiation & & & \\
& Unknown & $1.2 \%$ & $1.6 \%$ & \\
\hline
\end{tabular}

DLBCL, Diffuse large B-cell lymphoma; MALT, mucosal-associated lymphoid tissue; NHL, non-Hodgkin's lymphoma; CLL, chronic lymphocytic leukemia. 

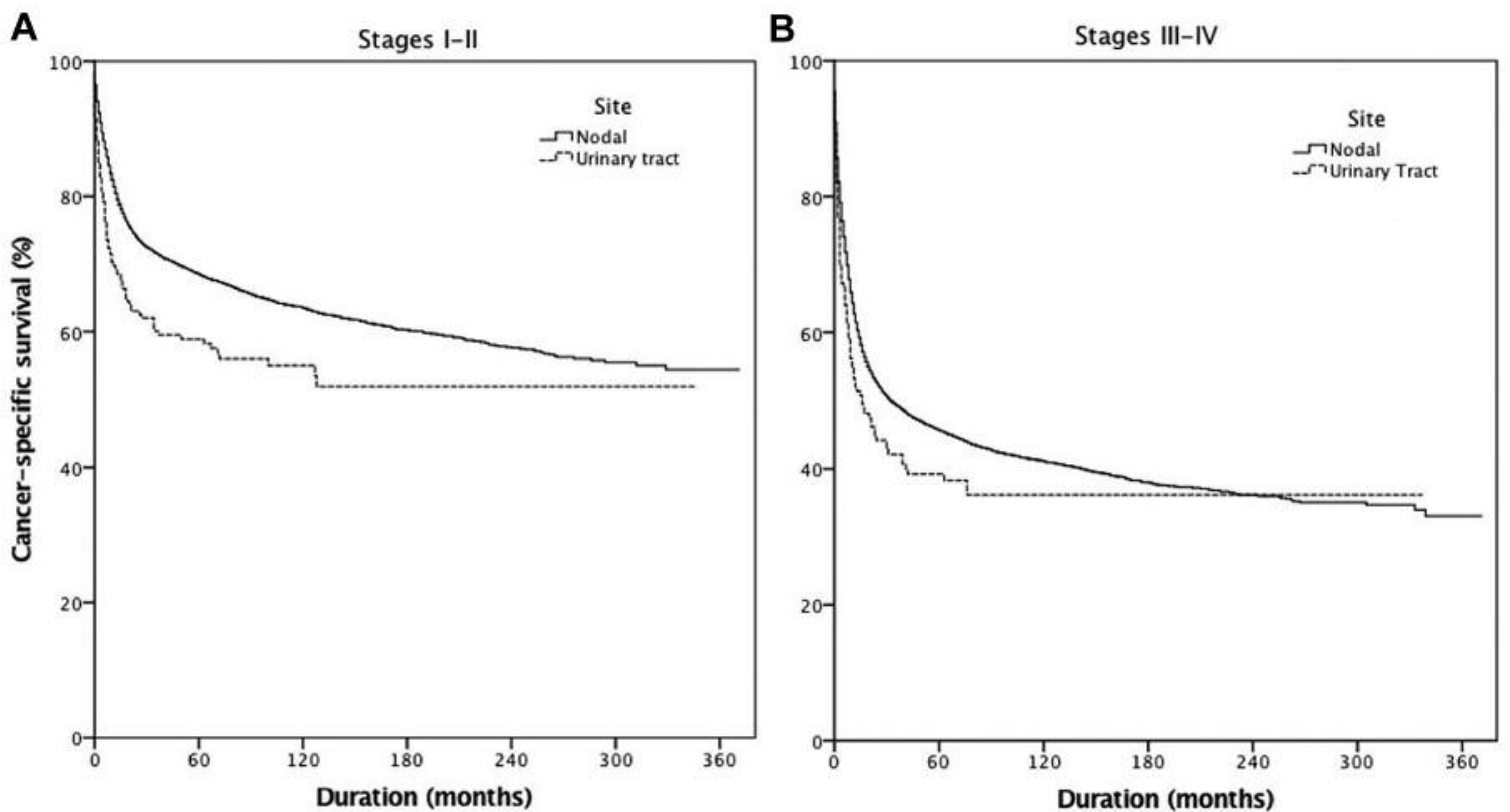

Figure 4. Cancer-specific survival of patients with stage I-II $(N=19173, p<0.001)$ (A) and stage III-IV diffuse large B-cell lymphoma (N=28,731, $p=0.03)(B)$ stratified by site. Five-year cancer-specific survival for patients with nodal and urinary tract diffuse large B-cell lymphoma was $69 \%$ and $59 \%$ for those with stage I-II and $46 \%$ and $39 \%$, respectively, for those with stage III-IV disease.

across the USA. Although the urinary tract does not have any organized lymphoid tissue, PUTL may originate from lymphoid cells attracted to the area from recurrent infections $(4,5)$. This hypothesis is supported by regression of some lymphomas in other parenchymal organs after the use of antibiotics, particularly MALT-associated lymphomas (13). In addition, the observation that bladder lymphomas occur more frequently in women than men could support the above theory since women experience cystitis more frequently than men. Moreover, higher frequency of MALT-associated lymphoma, which is commonly associated with bacterial infections (13), was noted in the bladder. A previous study failed to demonstrate an association between kidney lymphoma and Epstein-Barr virus infection (14). The most frequent symptoms in patients with kidney lymphoma are fever, weight loss, flank or abdominal pain, and hematuria (4), whereas the most frequent symptoms in bladder lymphomas are hematuria and recurrent urinary tract infections (5). Patients can have a flank mass on physical examination and may often present with acute kidney injury from renal parenchymal involvement or obstruction (15). While the differential diagnosis of lymphoma from other more common malignancies of the urinary tract can be difficult based solely on imaging, a small-scale study with 12 patients suggested that in contrast to most types of renal cell carcinoma, lymphoma usually has a high fludeoxyglucose uptake on positron-emission tomography scan (16). The use of percutaneous biopsy can safely and accurately provide histological diagnosis (17) and lead to early identification of kidney lymphoma. For bladder masses, cystoscopy with tissue biopsy can provide an accurate diagnosis (18).

Our data suggest that surgical treatment may be beneficial in patients with PUTL. This is notable, given that the mainstays of nodal DLBCL therapy are chemotherapy and radiation therapy (19). Surgery was most likely implemented for diagnostic purposes in the majority of patients, but it is possible that tumor debulking may produce survival benefit. Of note, Kim et al. similarly found that intestinal lymphoma benefits from surgery (20). Another study found that the most likely lymphoma to respond to local therapies is MALT-associated lymphoma of the bladder, which can recede even with administration of antibiotics (21). Surgery is occasionally used for MALT-associated lymphomas (22) but given that the analysis was multivariable and that DLBCL was the predominant form, the benefit should have been shared across all cases.

With regards to radiation therapy, it should be noted that the limitations of SEER radiation data can confound interpretation. The International Lymphoma Radiation Group includes in their guidelines "pelvic lymphoma involving bladder or gynecologic organs" and advises in favor of the use of radiation therapy. However, it does not outline any specific indications for lymphomas originating from the kidneys (23). In terms of chemotherapy, based on an analysis 
of the SEER database, Olsewski et al. argued that the location of extranodal NHL is critical for the effect of rituximab on the therapy, and that survival of patients with genitourinary lymphomas has not shown an improvement in the rituximab era (24). Our data are in agreement with this finding, however, the assumptions that after 2000 almost everybody received rituximab and that only the introduction of rituximab affected the survival are significant limitations.

Extranodal lymphoma has been shown to have worse prognosis than nodal (especially for DLBCL) depending on the tumor location. Castillo et al. demonstrated that gastrointestinal, pulmonary and liver/pancreas DLBCL carry a worse prognosis than nodal (6). In our analysis, after controlling for gender, patient age and race, disease stage and year of diagnosis, we showed for the first time that PUTL of DLBCL type is associated with worse CSS compared with primary nodal DLBCL in both early (I-II) and late (III-IV) stages. This could potentially be explained by the comorbidities that are caused by mass effect in the urinary tract (hydronephrosis) and infiltration of the renal parenchyma which leads to acute kidney injury. Any type of kidney injury in patients with cancer is associated with worse outcomes (25).

When comparing kidney with bladder lymphoma, a few differences were noted. Patients with bladder lymphoma were mainly female whereas those with kidney lymphoma were mainly male. Moreover, a higher frequency of MALTassociated lymphoma was noted in the bladder, which according to the literature is most commonly associated with bacterial infections (13). Contrary to kidney lymphoma, the majority of the bladder lymphomas were diagnosed at stage I. A possible explanation is the fact that bladder lymphoma gives rise to symptoms faster, mainly hematuria (5). More patients with bladder lymphoma underwent surgery and received radiation, which can be interpreted as being a result of the greater accessibility of the area for excisional biopsy when compared to the kidney. After controlling for multiple variables, no mortality difference was noted between the two sites. Finally, our data clearly disagree with the literature on the most common lymphoma of the bladder as it was found to be DLBCL and not MALT-associated as mentioned before (26).

Among the three most prevalent PUTL histology subtypes in our analysis, DLBCL carried the worse prognosis, whereas patients diagnosed with MALT-associated lymphoma had the best prognosis. Female gender was also independently associated with better survival. Similar data have been reported for B-cell lymphomas in the era of rituximab but were not noticed before supporting the fact that women may respond better to rituximab $(27,28)$. Age as categorized by NCCN-IPI (9) also has prognostic value for patients with PUTL.

The major strength of our study is the large number of patients $(>1,000)$ from a multi-institutional database that spans more than 30 years, minimizing selection bias. Limitations include the lack of information about chemotherapy regimens and the low quality of information on radiation treatment. Moreover, due to the lack of central pathology review, possible tumor misclassification cannot be excluded. It should be noted that the distinction between advanced-stage primary extranodal and nodal lymphoma can be challenging given that nodal disease can involve extranodal sites as it progresses (29). Different definitions can often alter the results of these studies (30). We propose the creation of an international multi-center clinical database that can further elucidate and verify our findings. Already, efforts from the International Extranodal Study Group have delineated the behavior and clarified the treatment of other rare types of extranodal lymphomas (31-33).

In summary, our study is the first to provide a detailed description of the demographic and clinical characteristics of patients with PUTL. We found that primary urinary tract DLBCL carries a worse prognosis than nodal DBLCL in both early and late stages. In addition, surgery may be beneficial for patients with PUTL. The survival of patients with PUTL in the past two decades has not improved significantly despite the introduction of modern therapies such as rituximab. Therefore, better therapies are needed.

\section{Acknowledgements}

Pavlos Msaouel is supported by the National Institutes of Health T32 CA009666 grant. Leonard Joseph Appleman is supported by the National Institutes of Health P30-CA47904 and UM1 CA186690-01.

\section{References}

1 https://seer.cancer.gov/statfacts/html/nhl.html. Accessed 05/2016.

2 Newton R, Ferlay J, Beral V and Devesa SS: The epidemiology of non-hodgkin's lymphoma: Comparison of nodal and extranodal sites. Int J Cancer 72(6): 923-930, 1997.

3 Jacobs A and Symington T: Primary lymphosarcoma of urinary bladder. Br J Urol 25(2): 119-126, 1953.

4 Chen X, Hu D, Fang L, Chen Y, Che X, Tao J, Weng G and Ye $\mathrm{X}$ : Primary renal lymphoma: A case report and literature review. Oncol Lett 12(5): 4001-4008, 2016.

5 Simpson WG, Lopez A, Babbar P and Payne LF: Primary bladder lymphoma, diffuse large b-cell type: Case report and literature review of 26 cases. Urol Ann 7(2): 268-272, 2015.

6 Castillo JJ, Winer ES and Olszewski AJ: Sites of extranodal involvement are prognostic in patients with diffuse large b-cell lymphoma in the rituximab era: An analysis of the surveillance, epidemiology and end results database. Am J Hematol 89(3): 310-314, 2014.

7 https://seer.cancer.gov/about/overview.html. Accessed 05/2017.

8 Noone AM, Lund JL, Mariotto A, Cronin K, McNeel T, Deapen $\mathrm{D}$ and Warren JL: Comparison of seer treatment data with medicare claims. Med Care 54(9): e55-64, 2016. 
9 Zhou Z, Sehn LH, Rademaker AW, Gordon LI, Lacasce AS, Crosby-Thompson A, Vanderplas A, Zelenetz AD, Abel GA, Rodriguez MA, Nademanee A, Kaminski MS, Czuczman MS, Millenson M, Niland J, Gascoyne RD, Connors JM, Friedberg JW and Winter JN: An enhanced international prognostic index (nccn-ipi) for patients with diffuse large b-cell lymphoma treated in the rituximab era. Blood 123(6): 837-842, 2014.

10 Coiffier B, Lepage E, Briere J, Herbrecht R, Tilly H, Bouabdallah R, Morel P, Van Den Neste E, Salles G, Gaulard P, Reyes F, Lederlin $\mathrm{P}$ and Gisselbrecht $\mathrm{C}$ : Chop chemotherapy plus rituximab compared with chop alone in elderly patients with diffuse largeb-cell lymphoma. N Engl J Med 346(4): 235-242, 2002.

11 Cronin DP, Harlan LC, Clegg LX, Stevens JL, Yuan G and Davis TA: Patterns of care in a population-based random sample of patients diagnosed with non-hodgkin's lymphoma. Hematol Oncol 23(2): 73-81, 2005.

12 Surveillance Research Program, National Cancer Institute SEER*Stat software version 8.3.4. http://www.seer.cancer.gov/ seerstat.

13 Raderer M, Kiesewetter B and Ferreri AJ: Clinicopathologic characteristics and treatment of marginal zone lymphoma of mucosa-associated lymphoid tissue (malt lymphoma). CA Cancer J Clin 66(2): 153-171, 2016.

14 Yasunaga Y, Hoshida Y, Hashimoto M, Miki T, Okuyama A and Aozasa K: Malignant lymphoma of the kidney. J Surg Oncol 64(3): 207-211, 1997.

15 Al-Salam S, Shaaban A, Alketbi M, Haq NU and Abouchacra S: Acute kidney injury secondary to renal large b-cell lymphoma: Role of early renal biopsy. Int Urol Nephrol 43(1): 237-240, 2011.

16 Ye XH, Chen LH, Wu HB, Feng J, Zhou WL, Yang RM, Bu ZB, Ding Y, Guan J and Wang QS: $18 \mathrm{f}-\mathrm{fdg}$ pet/ct evaluation of lymphoma with renal involvement: Comparison with renal carcinoma. South Med J 103(7): 642-649, 2010.

17 Caoili EM and Davenport MS: Role of percutaneous needle biopsy for renal masses. Semin Intervent Radiol 31(1): 20-26, 2014.

18 Satoh E, Miyao N, Tachiki H and Fujisawa Y: Prediction of muscle invasion of bladder cancer by cystoscopy. Eur Urol 41(2): 178-181, 2002.

19 Armitage JO: How i treat patients with diffuse large b-cell lymphoma. Blood 110(1): 29-36, 2007

20 Kim SJ, Kang HJ, Kim JS, Oh SY, Choi CW, Lee SI, Won JH, Kim MK, Kwon JH, Mun YC, Kwak JY, Kwon JM, Hwang IG, Kim HJ, Park J, Oh S, Huh J, Ko YH, Suh C and Kim WS: Comparison of treatment strategies for patients with intestinal diffuse large b-cell lymphoma: Surgical resection followed by chemotherapy versus chemotherapy alone. Blood 117(6): 19581965, 2011

21 Hughes M, Morrison A and Jackson R: Primary bladder lymphoma: Management and outcome of 12 patients with a review of the literature. Leuk Lymphoma 46(6): 873-877, 2005

22 NCCN Clinical Guidelines in Oncology: B-Cell Lymphomas. https://www.nccn.org/professionals/physician_gls/pdf/b-cell.pdf. Accessed 05/2017.

23 Yahalom J, Illidge T, Specht L, Hoppe RT, Li YX, Tsang R, Wirth A and International Lymphoma Radiation Oncology G: Modern radiation therapy for extranodal lymphomas: Field and dose guidelines from the international lymphoma radiation oncology group. Int J Radiat Oncol Biol Phys 92(1): 11-31, 2015.
24 Olszewski AJ, Winer ES and Castillo JJ: Improved survival with rituximab-based chemoimmunotherapy in older patients with extranodal diffuse large b-cell lymphoma. Leuk Res 38(8): 866$873,2014$.

25 Rosner MH and Perazella MA: Acute kidney injury in patients with cancer. N Engl J Med 376(18): 1770-1781, 2017.

26 Kempton CL, Kurtin PJ, Inwards DJ, Wollan P and Bostwick DG: Malignant lymphoma of the bladder: Evidence from 36 cases that low-grade lymphoma of the malt-type is the most common primary bladder lymphoma. Am J Surg Pathol 21(11): 1324-1333, 1997.

27 Riihijarvi S, Taskinen M, Jerkeman M and Leppa S: Male gender is an adverse prognostic factor in b-cell lymphoma patients treated with immunochemotherapy. Eur J Haematol 86(2): 124-128, 2011.

28 Ngo L, Hee SW, Lim LC, Tao M, Quek R, Yap SP, Loong EL, Sng I, Hwan-Cheong TL, Ang MK, Ngeow J, Tham CK, Tan MH and Lim ST: Prognostic factors in patients with diffuse large b cell lymphoma: Before and after the introduction of rituximab. Leuk Lymphoma 49(3): 462-469, 2008.

29 Yunus SA, Usmani SZ, Ahmad S and Shahid Z: Renal involvement in non-hodgkin's lymphoma: The shaukat khanum experience. Asian Pac J Cancer Prev 8(2): 249-252, 2007.

30 Krol AD, le Cessie S, Snijder S, Kluin-Nelemans JC, Kluin PM and Noordijk EM: Primary extranodal non-hodgkin's lymphoma (nhl): The impact of alternative definitions tested in the comprehensive cancer centre west population-based nhl registry. Ann Oncol 14(1): 131-139, 2003.

31 Ryan G, Martinelli G, Kuper-Hommel M, Tsang R, Pruneri G, Yuen K, Roos D, Lennard A, Devizzi L, Crabb S, Hossfeld D, Pratt G, Dell'Olio M, Choo SP, Bociek RG, Radford J, Lade S, Gianni AM, Zucca E, Cavalli F, Seymour JF and International Extranodal Lymphoma Study G: Primary diffuse large b-cell lymphoma of the breast: Prognostic factors and outcomes of a study by the international extranodal lymphoma study group. Ann Oncol 19(2): 233-241, 2008.

32 Sammassimo S, Pruneri G, Andreola G, Montoro J, Steffanoni S, Nowakowski GS, Gandini S, Negri M, Habermann TM, Raderer M, Li ZM, Zinzani PL, Adam P, Zucca E and Martinelli G: A retrospective international study on primary extranodal marginal zone lymphoma of the lung (balt lymphoma) on behalf of international extranodal lymphoma study group (ielsg). Hematol Oncol 34(4): 177-183, 2016.

33 Govi S, Christie D, Mappa S, Marturano E, Bruno-Ventre M, Messina C, Medina EA, Porter D, Radford J, Heo DS, Park Y, Pro B, Jayamohan J, Pavlakis N, Zucca E, Gospodarowicz M, Ferreri AJ and International Extranodal Lymphoma Study G: The clinical features, management and prognosis of primary and secondary indolent lymphoma of the bone: A retrospective study of the international extranodal lymphoma study group (ielsg \#14 study). Leuk Lymphoma 55(8): 1796-1799, 2014. 